Les relations commerciales entre le Levant espagnol, l'Europe occidentale et l'Amérique

Les exemples d'Alicante et Carthagène (1575-1700)

\title{
Vicente Montojo
}

\section{(2) OpenEdition}

\section{Journals}

Édition électronique

URL : http://journals.openedition.org/abpo/1891

DOI : $10.4000 /$ abpo. 1891

ISSN : 2108-6443

Éditeur

Presses universitaires de Rennes

Édition imprimée

Date de publication : 10 avril 2011

Pagination : 45-69

ISBN : $978-2-75351410-2$

ISSN : 0399-0826

Référence électronique

Vicente Montojo, « Les relations commerciales entre le Levant espagnol, l'Europe occidentale et I'Amérique ", Annales de Bretagne et des Pays de l'Ouest [En ligne], 118-1 | 2011, mis en ligne le 10 avril 2013, consulté le 30 avril 2019. URL : http://journals.openedition.org/abpo/1891 ; DOI : 10.4000/ abpo. 1891 


\title{
Les relations commerciales entre le Levant espagnol, I'Europe occidentale et l'Amérique : les exemples d'Alicante et Carthagène (1575-1700)*
}

\author{
Vicente Montojo MONTOJO \\ Docteur en histoire moderne (Université de Murcie) \\ Sociétaire et secrétaire général de I'Académie Alfonse X le Sage \\ Responsable technique des Archives Générales de la Région de Murcie
}

\begin{abstract}
Depuis les années 1960, les historiens et les chercheurs en histoire économique et sociale n'ont cessé de modifier le champ de leurs études qu'ils centrèrent tout d'abord sur le trafic et les échanges commerciaux puis sur les parcours de groupes de personnes et d'individus. Les mouvements des bateaux sont pratiquement absents des publications des cinquante dernières années, car on s'intéressait aux chiffres surtout du point de vue des lieux et des pays ${ }^{1}$.
\end{abstract}

La communauté marchande valencienne entre Anvers et Cadix (1538-1590)

Les recherches de Valentín Vázquez de Prada sur les commerçants valenciens d'Anvers montrent qu'ils formaient une petite communauté avec 7 membres en 1527, 4 en 1531, puis seulement 3 en 1561, tandis que les Castillans, d'après Joseph Maréchal, étaient bien plus nombreux (47 marchands en 1525 et 61 en 1562) ${ }^{2}$. Les Catalans disparurent quant

* Cet article a été élaboré grâce à la commission du Ve centenaire de la Communauté Autonome de Murcie en 1992 et s'intègre, depuis cette année 2010, aux projets de recherches Dyncoopnet, de la ESF (Budapest), coordonnés par Ana Crespo Solana (Espagne, CSIC) et Jack Owens (USA, Université de I'Idaho).

1. La traduction de cet article de l'espagnol vers le français a été réalisée par les soins de Laurey Braguier; la relecture en a été assurée par Michel Bochaca.

2. MARÉCHAL, Joseph, "La colonie espagnole de Bruges, du XIV e au Xvie siècle ", Revue du Nord, t. 35, 1953, p. 5-40. CASAdo Alonso, Hilario, El Triunfo de Mercurio. La presencia castellana en Europa (siglos xv y xvI), Burgos, Cajacírculo, 2003. 
à eux après la crise de la guerre civile de 1462-1472. Peu nombreux, les Valenciens étaient cependant très actifs. Ils tenaient divers livres de comptes, dont certains ont été conservés aux Archives municipales d'Anvers comme, par exemple, le livre de Dimas Ferrer datant des années 1538-1540. Nous savons grâce à ce livre et à différents actes notariés (voir tableau 1) qu'il y avait à Anvers une nation des marchands d'Aragon (1487-1494 et 1527-1550). II en existait auparavant une de marchands catalans qui avait son siège à Bruxelles. Elle était formée principalement par des Valenciens en rapport avec des marchands espagnols installés à Londres et à Cadix, eux-mêmes en relations d'affaires avec Palerme (Sicile), et comptait aussi quelques habitants de Ciutat de Mallorca (Palma de Majorque) ${ }^{3}$.

Les marchands et négociants valenciens d'Anvers géraient, entre autres, des lettres de change entre les foires de Medina del Campo et d'Anvers (paiements de foire à foire), le recouvrement de dettes à Londres ainsi que le transport de marchandises depuis Valence et Alicante vers Anvers, dont I'alun exploité à cette époque dans les mines de Tolfa (Rome), de Mazarrón (Murcie) jusqu'en 1572, d'Alumbres Nuevos (Carthagène) et de Rodalquilar (Almeria) ${ }^{4}$.

Les informations provenant du livre journal de Dimas Ferrer, Valencien installé à Anvers, témoignent également de l'importance du rôle d'intermédiaire joué par le port de Cadix dans le trafic entre la Flandre et l'Espagne méditerranéenne car il était courant que les produits parvenus à Cadix soient réexpédiés vers la Flandre, mais également vers Lyon où il eut recours aux services de Bonaventura Michaeli et Girólamo Arnolfini de Luca pour le paiement de lettres de change. Ainsi, Lyon, dont les foires prirent de l'importance dans la seconde moitié du xvle siècle lorsque le climat s'apaisa entre l'Espagne et la France, se convertit en point de confluence des intérêts et des affaires de marchands de Valence comme Baltasar Julia, dont le livre de comptabilité a été si important pour la compréhension de ses activités ${ }^{5}$, ou Juan Augier, marchand français de Valence qui traitait avec le Breton Julien Junge ${ }^{6}$.

Selon Henri Touchard, à la fin du $\mathrm{xv}^{\mathrm{e}}$ siècle des marins basques et bretons effectuaient le transport pour les échanges avec l'Angleterre. En 15731578 les Anglais commencèrent à s'aventurer eux-mêmes dans les eaux

3. VÁzQuez de PRAdA, Valentín, «La colonia mercantil valenciana en Amberes en la época de Carlos V ", Aportaciones a la historia económica y social : España y Europa, siglos XVI-XVIII, Pamplona, Eunsa, 2000, p. 207-227.

4. Muñoz Buendía, Antonio, "Los alumbres de Rodalquilar (Almería) : sueños y fracasos de una gran empresa minera del siglo XVI ", Los señoríos en la Andalucía Moderna. El Marquesado de los Vélez. Almería, Instituto de Estudios Almerienses, 2007, p. 463-490.

5. LAPEYRE, Henry, «El libro de cuentas de Baltasar Julia (1565) », Cuadernos de Historia de España, t. 51, 1970, p. 246-315.

6. LlORET I BADIA, Antoni, «El manual de Joan Augier (1597-1613) : aspectos contables », en Internacionalización de la empresa : un desafío para el 2000, VIII Congreso AECA (Sevilla, 27-29 septiembre 1995), vol. 1, Sevilla, 1995, p. 619-636. 
méditerranéennes ${ }^{7}$, jusqu'à ce que la guerre déclarée par Philippe II (15851598) à la mort de Marie Stuart, dans le contexte de la mise sur pied de I'Invincible Armada (1588), mette fin à leur trafic.

Entre 1550 y 1600 une vague d'émigration caractéristique de l'époque des guerres de Religion se produisit en Europe, entraînant la division des communautés commerçantes comme celle des Espagnols à Nantes ${ }^{8}$, des Français à Toulouse ${ }^{9}$ et dans les Pyrénées ${ }^{10}$, la diaspora flamande en Hollande et dans la monarchie hispanique ${ }^{11}$, celle de juifs portugais et de huguenots français à Hambourg ${ }^{12}$, ou celle encore naissante d'Irlandais et d'Anglais catholiques vers les villes d'Espagne ${ }^{13}$, de Flandres et de France. Ces mouvements d'émigration ont donné lieu à diverses interprétations, comme celles évoquant un exil politique ou la transmigration au sein de réseaux marchands. Nous pourrions ajouter une migration plus singulière encore à celles que nous venons de mentionner, correspondant au déplacement de Français (Béarnais, Bretons, Lyonnais et Marseillais) vers les ports du Levant méditerranéen espagnol, et qui constitue le témoignage de diverses facettes identitaires.

7. BRAUDEL, Fernand, El Mediterráneo y el mundo mediterráneo en la época de Felipe II, México, Fondo de Cultura Económica, 1976, p. 68. Montoso Montoso, Vicente, « La escribanía municipal de Cartagena (1573-1578) : nueva perspectiva sobre un retablo inglés y el comercio », Cartagena histórica, t. 29, Cartagena, 2009, p. 44-49.

8. SAUPIN, Guy, "Les marchands espagnols dans l'élite dirigeante du Conseil des bourgeois de Nantes au milieu du xvl ${ }^{\mathrm{e}}$ siècle », Annales de Bretagne et des Pays de l'Ouest, t. 12, $n^{\circ} 4,2005$, p. 157-181.

9. BRUMONT, Francis, "La géographie du commerce des draps à Toulouse au milieu du $x \mathrm{xI}^{\mathrm{e}}$ siècle », Annales du Midi, t. 236, 2001, p. 497-508. BrumONT, Francis et LARGUIER, Gilbert, "Trois lettres marchandes de Pierre Assézat (1575) », Annales du Midi (Le commerce du pastel du xve au XVII e siècle), t. 222, 1998, p. 237-245. BRUMONT, Francis, « Politique, religion et affaires: Pierre Assézat (vers 1515-1581) », Annales de Bretagne et des Pays de l'Ouest, t. $12, n^{\circ} 4,2005$, p. 147-156.

10. DeSPLAT, Christian, «Les Pyrénées basco-béarnaises : d'une frontière de chrétienté à une frontière de catholicités (milieu XVI ${ }^{\mathrm{e}}$ siècle-fin $\mathrm{xVIII}{ }^{\mathrm{e}}$ siècle) », Revue de Pau et du Béarn, t. 30, 2003, p. 51-82.

11. Stols, Edy, De Spaanse Brabanders en de handelsbetrekkingen der Zuidelijke Nederlanden met de Iberische wereld, 1598-1648, Brussel, Paleis der Academien, 1971. FAGEL, Raymond, De Hispano-Vlaamse wereld. De contacten tussen Spanjaarden en Nederlanders, 1496-1555, Bruselas, Nimega, Archief en-Bibliotheekwezen in Belgie, 1996.

12. WeBER, Klaus, «Were merchants more tolerants? Godless Patrons of the Jews an the Decline of the Sephardi Community in Late Seventeeth-Century Hamburg ", Jewish Culture and History, $n^{\circ} 7 / 1-2,2004$, p. 77-92. WEBER, Klaus, « La migration huguenote dans le contexte de l'économie atlantique (L'exemple de Hambourg, 1680-1800) », en Guido Braun/Susanne LACHENICHT, Les États allemands et les huguenots, Munich, Oldenbourg, 2007, p. $125-136$.

13. Montojo Montojo, Vicente, "Comunidades atlánticas en el Sureste español », en Crespo Solana, Ana (coord.), Comunidades transnacionales. Colonias de mercaderes extranjeros en el Mundo Atlántico (1500-1830), Madrid, Doce Calles, 2010, p. 143-153. Montojo Montojo, Vicente, «Immigration et groupes de pouvoir dans le Levant espagnol », COSTE, Laurent (dir.), Liens de sang, liens de pouvoir. Les élites dirigeantes urbaines dans l'Europe occidentale et dans les colonies européennes (fin $\mathrm{XV}^{\mathrm{e}}$-fin XIX siècles), Rennes, PUR, p. 95-108. 
Les marchands du royaume de Valence avaient cessé d'aller dans les Flandres au milieu du $x v l^{e}$ siècle. Seuls quelques-uns continuèrent à y demeurer comme Juan de Camarena (1553-1578), Alonso de Camarena et Miguel Camarena, trois frères qui s'y maintinrent entre 1580 et 1603, en important tout d'abord de l'alun puis du vin, parfois d'Alicante avec d'autres produits en collaboration avec Mucio Palavicino, de Madrid, beaufrère d'Alonso de Camarena ${ }^{14}$. Ils vécurent la grande instabilité politique et sociale des années 1555-1559 et 1567-1585, qui toucha non seulement la France mais aussi les Flandres (1567-1607) et affecta l'Espagne avec la perte de Bougie (1555), le siège d'Oran (1563) et la révolte des Morisques des Alpujarras (royaume de Grenade, 1568-1570). Par ailleurs, la guerre d'Italie (1557) et la révolte du peuple génois contre la vieille noblesse (1572) entraînèrent de nouveaux déplacements vers la péninsule lbérique, ce qui accrut un courant migratoire déjà en place depuis quelques décennies.

Tandis que la communauté valencienne d'Anvers diminuait, l'installation d'Italiens et de Français augmentait dans les royaumes de Valence ${ }^{15}$ et de Murcie. Les Français et les Génois établis à Alicante et à Carthagène formèrent fréquemment des compagnies ou des sociétés et une coopération s'établit avec les marchands valenciens comme en témoignent les livres de comptes du Génois Giovanni Carpeneto d'Alicante (1537-1590), du Valencien Baltasar Julia qui était en relation avec Lyon, et de Jean Auger, négociant français établi à Valence (1597-1613). On peut aussi faire état des livres de correspondance comme celui de Felipe Moscoso (Alicante, 1660-1685), ou bien encore des livres de comptabilité de Simón Rodríguez Moreira (Lorca, 1679-1681), d'origine portugaise et sans doute juif converti car ses papiers furent saisis par l'Inquisition.

Les ports du Levant méditerranéen (Valence, Alicante, Carthagène, Almería) donnèrent naissance à un trafic entre l'Espagne et l'Italie (Venise, Naples, Livourne, Gênes) qui trouvait son origine dans la sécurité qu'offrait la route des îles (Corse, Sardaigne et Baléares), dont la vitalité se manifeste par l'approvisionnement céréalier de Sienne en 1529, mais également en retour par une offre de produits variés (papier, acier, verre, tissus, produits manufacturés, céréales, sel, etc.). Cela leur permit d'enrichir leur trafic par des connexions avec d'autres grandes routes comme celles d'Oran (royaume de Berbérie, aujourd'hui en Algérie), d'Andalousie (royaume de Séville) ou avec le Portugal et l'Océan Atlantique. Au milieu du xvle siècle, Alicante obtint un avantage fiscal qui lui permit d'améliorer nettement sa situation économique et de former un nouvel axe commercial avec Livourne ${ }^{16}$.

14. Vázquez de Prada, Valentín, Lettres marchantes d'Anvers, Madrid, SEVPEN, 1960, t. I, p. 228-229.

15. Poitreneau, André, "La inmigración francesa en el Reino de Valencia (ss. XVI-XIX) », Moneda y Crédito, n 137, 1976, p. 103-133.

16. VÁZQUEZ DE PRADA, Valentín, "La actividad económica del Levante español en relación con Italia a finales del siglo XVI », VI Congreso de Historia de la Corona de Aragón, Madrid, 1959, p. 901-915. 
On considère habituellement que les relations entre les ports du Levant et l'Amérique aux $x \mathrm{VI}^{\mathrm{e}}$ et $\mathrm{XVII^{ \textrm {e } }}$ siècles ont été peu nombreuses dans un premier temps. Cette hypothèse semble fondée, notamment si on s'appuie sur les archives utilisées jusqu'à présent et qui proviennent principalement des Archives Générales des Indes, exception faite des protocoles notariaux de Málaga de la fin du $x v^{\mathrm{e}}$ siècle et du début $d u x \mathrm{I}^{\mathrm{e}}$ siècle. Les registres d'embarquement des Archives Générales des Indes sont cependant insuffisants car les informations sur les propriétaires des navires, les marchands affréteurs et l'origine des marchandises sont peu nombreuses. Les archives notariales de Carthagène contiennent des contrats d'affrètement de bateaux en partance pour l'Amérique et d'autres relatifs à ce trafic, mais le faible nombre de trajets directs n'est pas significatif de l'essor des ports du Levant espagnol entre le milieu du $x l^{e}$ siècle et celui du $x v I^{e}$ siècle. D'autre part, le trafic était indirect car contrôlé par les ports détenant le monopole, Séville et Cadix. Bien que Charles-Quint ait étendu le droit de commercer directement avec l'Amérique à Málaga, Carthagène, La Corogne, Bayona, Avilés, Laredo, Bilbao et Saint-Sébastien, le monopole au profit de Séville et de Cadix fut rétabli en $1573^{17}$. Málaga parvint toutefois à devenir port d'accueil de la flotte à son retour des Indes ${ }^{18}$.

\section{Évolution des communautés marchandes}

du Levant méditerranéen (1575-1700)

Le dernier quart du Xvle siècle (1575-1600)

Au cours du dernier quart $d u x v l^{e}$ siècle et des deux premières décennies du $x \mathrm{xII}^{\mathrm{e}}$ siècle, le trafic maritime des ports du Levant méditerranéen s'accrut non seulement avec la péninsule italienne, suite à la chute du trafic direct des ports castillans de la façade cantabrique avec les Flandres et I'Angleterre, mais également avec Cadix, Séville et les territoires en lien avec ces derniers, I'Europe Occidentale et l'Amérique ${ }^{19}$.

Une des principales manifestations de cette reprise commerciale fut l'installation de nombreux marchands de diverses origines. À Alicante, l'augmentation du nombre de marchands, surtout étrangers, entraîna en 1591 la nomination par le conseil municipal d'un juge créancier, afin de protéger les natifs en matière d'affaires marchandes, dans une ville où s'étaient installés les consulats de Gênes, Florence, Naples, Malte, Raguse et Venise, mais aussi de France, de Hollande et d'Angleterre ${ }^{20}$. À Carthagène, on

17. Lorenzo Sanz, Eufemio, Comercio de España con América en la época de Felipe II, Valladolid, Instituto Cultural Simancas, 1979, t. I, p. 305-306.

18. Haring, Charles H., Comercio y navegación entre España y las Indias en la época de los Habsburgos, México, Fondo de Cultura Económica, 1918, p. 18-21.

19. Mas Galvañ, Cayetano, "Artesanía, manufacturas y actividades comerciales », en Historia de la Provincia de Alicante, Murcia, Ediciones Mediterráneo, 1986, p. 125-212, cfr. 170.

20. Figueras Pacheco, Francisco, El Consulado Marítimo y Terrestre de Alicante y Pueblos del Obispado de Orihuela, Alicante, Instituto de Estudios Alicantinos, 1957, p. 39 et 51. 
comptait en plus des Espagnols (Tolédans, Andalous, Navarrais, Catalans et Valenciens) de nombreux Génois (ils étaient une centaine entre 1560 et 1610), des Florentins, des Milanais, des Portugais, des Flamands et surtout des Français, parmi lesquels des Bretons.

Ces étrangers s'associèrent parfois aux Castillans. Á Carthagène, le Breton Julien Jonché - en castillan Julián Junge - originaire de Saint-Malo, travailla avec Damián Bolea, marchand et juré de la municipalité, fils de Ginés de Bolea (lui-même juré en 1558), pour exporter de l'alun et de la salicorne. Ils commercèrent également avec Pedro de Lao ou « La O » à Oran et Cadix, ainsi qu'à Lisbonne. Julián Junge réussit à s'installer grâce à son mariage avec la fille de Damián Bolea. D'autres marchands natifs formèrent des associations familiales ou des compagnies avec des marchands de Gênes, Venise ou Saint Malo. II en résulta dans les années 1575-1580 une forte augmentation de l'installation d'étrangers, pour la plupart marchands. Cet afflux d'étrangers, surtout Génois, suscita en 1575 I'inquiétude du conseil de Carthagène qui voyait en eux " des facteurs d'autres marchands qui résident à Gênes et à Naples et dans d'autres parties hors de ces royaumes ${ }^{21}$ ». Les Génois ne furent pas pour autant en butte à la rancœur des locaux. En 1564 la municipalité défendit des Portugais qui faisaient le commerce de la morue et furent soumis injustement à une amende par l'alcalde mayor ${ }^{22}$.

Le malouin Julián Junge se détache par le nombre élevé de ses créditeurs et de ses clients. II jouissait peut-être de la réputation de bon gestionnaire et de bon facteur attribuée à de nombreux marchands ${ }^{23}$. Si les Français ne se distinguent pas par leur nombre, très inférieur à celui des Génois, ils eurent cependant une grande importance économique et sociale. L'introduction de la fabrication du savon à Alicante et à Carthagène par Julián Junge témoigne de leur dynamisme. Ce dernier a été probablement le marchand le plus important durant les deux dernières décennies $d u x \mathrm{l}^{\mathrm{e}}$ siècle grâce à la variété de ses affaires (alun, corail, savon, laine, salicorne, blé, esclaves, épices, etc.) mais aussi à son activité financière (achat de rentes royales, de salines). Remarquablement riche, il fut armateur, propriétaire de nombreux bateaux et il possédait des agents commerciaux dans de nombreux ports des côtes atlantique et méditerranéenne, en plus des membres de sa propre famille à Saint-Malo, ce qui explique son intervention directe dans le commerce avec l'Amérique. Julián Junge fait référence dans son testament à la compagnie qu'il avait avec ses frères à Saint-Malo et à ses agents présents à Venise, Palerme, Gênes, Séville, Lisbonne ${ }^{24}$. En 1581, son beau-père Damián Bolea donna pouvoir dans la ville de Mazarrón à Gabriel

21. Archivo municipal de Cartagena (Arch. mun. Cartagena), Acta Capitular (Ac. Cap.) 22-1-1575.

22. Arch. mun. Cartagena, Ac. Cap. 18-3-1564.

23. BENNASSAR, Bartolomé, "Facteurs sévillans au $x \mathrm{xl}{ }^{\mathrm{e}}$ siècle d'après des lettres marchandes », Annales Économie Société Civilisation, t. 12, 1957. p. 60-70. RINGROSE, op. cit., p. 276.

24. Arch. prov. de Murcia, Prot. 5359, $f^{\circ} 241 v^{\circ}-253 r^{\circ}, 13-9-1600$. 
Dufer, agent français de Julián Junge à Cádiz, pour vendre 600 quintaux d'alun qu'il avait expédiés avec l'aide de Cristóbal de Villarreal afin qu'ils soient vendus ou envoyés à Saint-Malo à I'attention de Guillermo Junge ${ }^{25}$. Julián Junge fit également affaire avec Pedro de Lao, marchand flamand de Cadix ${ }^{26}$, et avec Abraham Vangermes, son représentant en 1600, flamand et résidant à Carthagène en 1630. Malgré l'inimitié de certains échevins et les accusations de collaboration avec les Anglais qui pesaient sur lui, il obtint du conseil de la ville de Carthagène le certificat de son ascendance noble et chrétienne le 6 septembre $1590^{27}$. Julián Junge et d'autres commerçants français formèrent des compagnies très actives, dont certaines étaient familiales. Ainsi, Julián Coronel et Julián Preste, respectivement cousin et gendre de Julián Junge, furent ses collaborateurs et contribuèrent à créer d'étroites relations entre Alicante, Carthagène, Valence, Saint-Malo et Marseille de 1580 à 1600 . Signe d'un statut social élevé, tous étaient hidalgos ou échevins et siégeaient au conseil municipal de Carthagène.

Il est important de souligner par ailleurs que la majeure partie des activités de ces marchands se centra principalement sur le trafic maritime et avec des marchands qui n'étaient pas de Carthagène, c'est-à-dire dans un cadre extérieur à celui de la ville. Les déclarations des marchands les plus importants de Carthagène en 1586 sont très claires sur ce sujet. Cristóbal de Villarreal affirma que la totalité de ses ventes était réalisée auprès d'habitants d'autres régions ou d'étrangers; pour Leonardo de Castro il s'agit des trois quarts de ses ventes, la moitié pour les associés Juan de Segovia et Juan Rodríguez, ainsi que pour Julián Junge et Pedro Francisco Panés, enfin entre le quart et le cinquième pour Esteban Espínola. À cette époque, Carthagène était surtout un port d'escale entre I'Atlantique et I'Italie. L'exportation des produits de Carthagène, de Murcie ou de Castille représentait une faible part au regard du trafic maritime en provenance d'autres villes (toile et morue de Saint-Malo, épices d'Orient, sucre et teintures des Amériques...). Valence, plus peuplée qu'Alicante et Carthagène, s'affirma comme un centre de consommation important, ce qui explique le grand nombre de Français qui s'y installèrent (22 en 1525-1549). Parmi les 43 Français qui y habitèrent entre 1556 et 1598, il y eut 10 Lyonnais, 7 Béarnais, et 2 Bretons ${ }^{28}$. Andrea Scorcia d'Alicante, Pelegro Castellón de Gênes et Julián Junge de Carthagène entretinrent des liens étroits avec eux.

25. Arch. prov. de Murcia, Prot. 10778, f $^{\circ} 92 \mathrm{r}^{\circ}-93 \mathrm{r}^{\circ}, 25-8-1581$.

26. Pedro de Lao ou La O hijo fonda le patronage de la naction flamande à Cadix : CRESPO SOLANA, Ana, "El Patronato de la nación flamenca gaditana en los siglos XVII y XVIII : trasfondo social y económico de una institución piadosa ", Studia historica ( $\mathrm{H}^{\mathrm{a}}$ Moderna), $\mathrm{n}^{\circ} 24$, Salamanca, 2002, p. 297-329.

27. Montojo Montojo, Vicente, "Mercados y estrategias mercantiles en torno a Cartagena en el siglo XVI y primera mitad del XVII : un microanálisis », Cuadernos del Estero Revista de Estudios e Investigación, n 7-10, Cartagena, 1992-1995, p. 143-202.

28. Salvador Esteban, Emilia, "Mercaderes extranjeros en la Valencia de los siglos xVI y xVIII. Entre la atracción y el rechazo », en Congreso Internacional La Burguesía española en el Antiguo Régimen (Madrid, 1991), Valladolid, Universidad de Valladolid, 1996, p. 11381155, cfr. 1144-1145. 
Selon une enquête réalisée à Carthagène en 1612, trois Français et un Flamand s'y étaient installés entre 1596 et 1611 , mais en réalité ils furent plus nombreux. Parmi les étrangers connus on note la présence de Joselín Coronel, cousin de Julián Junge, de Julián Preste et Beltrán Roquez, neveux de Junge, de Gabriel Cue, Juan Bautista Cue, Lorenzo Grutt, Joselín Hazou, Julián Launay Langaván, vivant à Carthagène en 1594; Pedro Pepín, Breton, et Juan del Poyo, Béarnais, qui régnèrent sur le marché des draps et de la toile au début du $\mathrm{XVII}^{\mathrm{e}}$ siècle, y compris à Murcie, en exportant de la laine et de la salicorne. La présence de marchands français installés à Alicante, Carthagène et Valence était importante entre 1596 et 1630.

Julián Launay Langaván fut désigné consul de France à Carthagène (1596) par les consuls de Marseille et les villes de Bretagne. La rupture des relations diplomatiques entre l'Espagne et la France (1593-1598) provoqua I'interruption du trafic entre la Bretagne et la Provence, car ces territoires firent partie de la Ligue Catholique (Saint-Malo se rendit à Henri IV en 1594). C'est ainsi que Julián Launay à Carthagène et Jacques Joyset à Valence choisirent de se faire naturaliser et de devenir sujets de Philippe II, ce qui n'était pas sans difficulté comme en témoignent les accusations d'espionnage dont dut se défendre Launay ${ }^{29}$. Malgré cela, ou peut-être grâce à cela, Julián Junge et Julián Launay furent des fournisseurs de céréales qu'ils vendirent en grandes quantités au conseil de la ville de Carthagène (1594), puis à des habitants de Blanca qui en achetèrent en 1605 à Launay, alors facteur de Ginés Molina Cachopo ${ }^{30}$.

Les guerres de la Valteline et de Monferrat (1626-1631) interrompirent les relations avec la France mais les Français ne disparurent pas pour autant de la ville. Ils s'y maintinrent jusqu'à la rupture définitive de 1635. Entre 1627 et 1632 les Génois de Carthagène maintinrent leurs exportations de laine et de salicorne, mais ce fut également le cas de Joselin Haçou, un marchand français qui exportait de la laine et du savon. Dans les années qui suivirent, Alicante et Carthagène se convertirent en avant-ports de Valence. En 1630, les Génois organisèrent une flotte commerciale avec leurs propres bateaux, comme cela avait déjà été le cas en 1624 pour les échanges entre les Flandres, les provinces septentrionales, l'Andalousie et le royaume de Grenade. Cela démontre la présence à Carthagène de marchands aisés, capables d'armer plusieurs bateaux contre Alger tout en restant par ailleurs très actifs. Ils essayèrent de former une compagnie privilégiée du Levant pour le commerce méditerranéen (ses deux chambres se situaient

29. Descimon, Robert, RuIz IBÁÑEZ, José Javier, Les Ligueurs de l'exil. Le refuge catholique français après 1594, Seyssel, Champ Vallon, 2005. p. 112-113.

30. Alonso Alcayde, Alonso Pinar el viejo et Fernando Aguilar s'engagèrent par la présente à rembourser à Ginés de Molina Cachopo, alcalde de Blanca, 600 réaux qu'ils doivent payer à Julián Launay à Carthagène : Arch. prov. de Murcia, Prot. 9354, f० 131, Blanca 11-5-1605; voir : GARCíA AviLÉs, José Mă, Los moriscos del valle de Ricote, Alicante, Universidad de Alicante, 2007, p. 59. 
à Barcelone et à Carthagène). La compagnie du Levant fut approuvée par le conseil d'État en 1634, après l'acceptation en 1630, par 14 marchands, du projet proposé en 1626 au conseil municipal de Barcelone par l'assemblée des compagnies commerciales. Pere Molas lia le développement de l'amirauté avec celui de la compagnie de commerce et usa de divers moyens pour renforcer le commerce espagnol. Par ailleurs, d'autres marchands participèrent à l'organisation de flottes pour les Indes.

Les communautés marchandes de Carthagène étaient dépendantes d'autres groupes de marchands, notamment les Génois de Grenade et de Huéscar quant à l'exportation de laine, et les Génois d'Alicante et de Valence concernant l'importation de produits alimentaires et manufacturés. De fait, Robert Blanes, qui a travaillé sur les registres des péages maritimes de Valence, a mentionné un grand nombre d'exportations réalisées par ces communautés depuis Alicante et Carthagène. À l'origine de ce développement tardif, entre 1620 et 1630 , il faut souligner le rôle de marchands des villes du Levant et la variété de leur provenance. À la fin de l'épidémie de peste noire de 1648 , certains témoignages montrent cependant le marasme des années précédentes car cette ville comptait tout au plus 5 ou 6 marchands et ceux-ci n'étaient guère fortunés. Commis de marchands étrangers qui les envoyaient sur place pour vendre leurs marchandises, leur activité était principalement celle de laboureurs ou de pêcheurs grevés par de nombreuses charges ${ }^{31}$.

Les conseils municipaux rencontrèrent des difficultés pour affermer les impôts et les rentes à l'exemple de l'alcabala à Carthagène en 1636. La ville déclara que les intempéries, la faiblesse du commerce maritime, la contagion venue du royaume d'Angleterre et les guerres qui opposaient ce pays à la France avaient empêché la perception des alcabalas et autres impôts, mais qu'il était nécessaire de mettre à ferme l'alcabala même si on craignait qu'il n'y eût point d'enchérisseur qui avançât la somme suffisante ${ }^{32}$. La paralysie du trafic marchand fut l'une des multiples conséquences de ce marasme économique : la population chuta en Espagne et en Italie et la production s'effondra comme, par exemple, celle de draps fins de Florence et Venise. On note également un appauvrissement général des populations suite à la guerre, à la famine, aux épidémies, à la pression fiscale et à la dévaluation de la monnaie à la fin de $\mathrm{XvII}^{\mathrm{e}}$ siècle. La dévaluation de la monnaie castillane (1628) fit fuir les principaux marchands de Carthagène vers Alicante et Valence car la monnaie valencienne était stable.

Cependant, même si la crise frappait une grande partie de la Méditerranée occidentale, Gênes et Venise étant durement touchées, la baisse du trafic affecta avant tout les ports du nord-ouest de la péninsule

31. Archivo Histórico Nacional (Madrid), Consejos, leg. 51.120, exp. 2, cit. por TORRES SÁNCHEZ, Rafael, Ciudad y territorio, El desarrollo demográfico de Cartagena durante la edad moderna, Cartagena, Ayuntamiento de Cartagena, Real Academia Alfonso X el Sabio, 1990, cfr. 580 nota 33.

32. Arch. mun. Cartagena, caja 112, $n^{\circ} 2,1642$, cabildo de 16-12-1636. 
ibérique car les Anglais et les Hollandais coupèrent le trafic maritime entre Bilbao et Anvers (1580). Les ports des royaumes de Valence, Murcie et Séville parvinrent à se maintenir jusqu'en $1620^{33}$. Les paix signées avec la France (paix des Pyrénées en 1659), l'Angleterre (mort de Cromwell) et le Portugal (1668) permirent la reprise du commerce. Les quatre guerres franco-espagnoles sous les règnes de Louis XIV et de Charles II n'empêchèrent pas le maintien sur place de marchands français : des Bretons à Alicante (Julián Loquet, Francisco Marbeuf) et des Béarnais à Carthagène, dans un contexte pourtant dominé par les Marseillais et les Provençaux.

\section{Les relations avec l'Atlantique et l'Amérique}

Les régions qu'unissaient les routes maritimes ou terrestres à Alicante et à Carthagène furent durant les $x v^{e}$ et $x v l^{e}$ siècles à la fois péninsulaires, méditerranéennes et atlantiques, tout en conservant entre elles une plus ou moins grande proximité. En Méditerranée, elles dépassèrent rarement le bassin occidental si l'on tient compte de l'importance des distances et de la domination turque sur la partie orientale, de l'Anatolie jusqu'à Tunis. Cependant, des relations plus étroites s'étaient établies depuis longtemps entre la Méditerranée et l'Atlantique, à tel point que le trajet entre I'Italie, la péninsule Ibérique, les Flandres et l'Angleterre, était devenu un axe commercial de premier ordre, qui intégra à la fin $d u x^{e}$ siècle la route des Amériques. L'état physique des hommes mais également le type et les moyens de transport déterminaient les distances à parcourir. Les voyages et les expéditions constituent une réalité perdue, étrangère à toutes les données temporelles actuelles dans le sens où, aujourd'hui, les distances se sont raccourcies. La rentabilité économique du transport maritime (plus rapide et avec une plus grande capacité de chargement) primait généralement sur le transport terrestre, mais l'insécurité des guerres et la piraterie limitèrent parfois ces avantages. Par ailleurs il faut prendre en compte le type, la qualité et le coût du produit que pouvaient altérer la distance à parcourir et le type de transport (son prix et sa qualité).

La Méditerranée occidentale fut l'un des principaux espaces du trafic maritime d'Alicante et de Carthagène. Dans les années 1550-1570, certains bateaux affrétés à Cadix eurent comme destination Alicante qui était généralement la ville d'escale pour les navires en partance vers Barcelone et I'Italie (Gênes, Civitavecchia), mais aucun ne fit route vers Carthagène. Les marchands qui louèrent les flottes furent surtout des Catalans (Francisco Barbarán, Jaime Calvet, Pedro Leal, Pedro Vilar, Juan Vendrel) et des Génois (Lázaro Pielo, Jerónimo Pinelo, Jerónimo Capriata, Tomás Cibo, Jerónimo

33. Valencia, Alicante, Málaga y Cartagena apenas conocieron decadencia comercial en el siglo XVII según : CASTILLO, Álvaro, "El gran comercio: puertos, rutas, tráfico », en Historia de España, dir José Ma Jover Zamora, t. 23, Madrid, Espasa Calpe, 1989, p. 356-361, cfr. 387. QUINTANA TORET, Francisco Javier, «El circuito de la Andalucía Oriental : La actividad comercial de Málaga en el siglo XVII », Jábega, n. 52, Málaga, 1986, p. 21-31. 
Grillo, Agustín Espínola, Agustín Pelerio). Il y avait quelques Castillans (Pedro Castillo, Domingo Simón), Florentins (Francisco de Santi) et des Majorquins (Benito Gil), mais très peu étaient d'Alicante (Pedro Pascual). L'intervention des Catalans fut notable à partir de 1550 et celle des Génois dans les années 1560-70. Tous cherchèrent à participer au transport du poisson (depuis Barbate, Cadix, Conil et Faro), au commerce des édulcorants (sucre) et des teintures (cochenille), comme à l'activité du prêt. Seul Pedro Vilar s'intéressa aux produits manufacturés (voir tableau 2) ${ }^{34}$.

Au cours des deux premières décennies du xvII siècle, près des deux tiers des bateaux qui entrèrent dans le port de Carthagène provenaient de ports méditerranéens tandis que l'Atlantique fournissait seulement le tiers de ce trafic ${ }^{35}$. Cette première impression pourrait être trompeuse car elle $n^{\prime}$ indique pas le volume des marchandises mais uniquement le type de bateaux. En 1605-1606, 97 navires et 169 saetías ${ }^{36}$ arrivèrent à Carthagène en provenance des ports méditerranéens contre 80 navires et 27 saetías venant de ports atlantiques, tandis qu'en 1612-1613, 51 navires et 80 saetías vinrent de la Méditerranée contre 57 navires et 33 saetías de l'Atlantique, ce qui marque ainsi la nette supériorité des relations et des échanges avec l'aire méditerranéenne.

Concernant les échanges commerciaux entre Carthagène et le bassin méditerranéen, on notera l'importance de la France au début du XVII ${ }^{\mathrm{e}}$ siècle, plus précisément de la Provence. Ces échanges reposaient sur deux types de productions, industrielles avec des acheminements depuis Marseille, mais également alimentaires avec l'exportation de céréales, de fruits et de légumes secs d'Arles, La Ciotat, Six Fours, Martigues et Toulon. Carthagène exportait principalement des minerais vers cette région ${ }^{37}$. Les relations avec I'Italie sont encore plus significatives du point de vue des exportations et des importations au cours du xvl ${ }^{\mathrm{e}}$ siècle. Le trafic était dominé par Gênes et Livourne dans tous les secteurs (hommes, bateaux et productions) et, dans une moindre mesure, par la Sicile tant en volumes que qualitativement (produits manufacturés raffinés très appréciés par Carthagène).

La documentation ne permet pas de quantifier le trafic maritime de Carthagène durant le $\mathrm{xvl}^{\mathrm{e}}$ siècle mais il est probable que les Flandres et l'Angleterre constituèrent les principaux marchés atlantiques jusqu'aux années

34. RoJAS VACA, Ma Dolores, Una escribanía pública gaditana del siglo XVı (1550-1570) : análisis documental (arrendamientos y compraventas), Cádiz, Universidad de Cádiz, 1993.

35. Sur cette période, nous possédons quatre registres relatifs aux entrés des embarcations dans le port de Carthagène qui couvrent les années 1603-1604, 1605-1606, 1612-1613 et 1616-1617 (Arch. mun. Cartagena, caja 95, $n^{\circ} 18$; caja 96, $n^{\circ} 6$; caja 44, $n^{\circ} 17$ ). II s'agit de registres établis par la greffe des douanes.

36. Embarcation latine à trois mâts et un seul pont, plus petite que le chébec et plus grande que la goélette, qui servait pour la course et le commerce (Diccionario de la lengua española, Madrid, Real Academia española, 1970, art. « saetía »).

37. Montojo Montojo, Vicente, "Las alternativas de la evolución económica de Cartagena durante los siglos XVI y XVII », dans MAS GARCíA, Julio (dir.), Historia de Cartagena, t. VII, Murcia, Ediciones Mediterráneo, 1986, p. 141-208. 
1565-1568 où la guerre mit fin aux exportations d'alun venant de Carthagène et de Mazarrón, et aux importations de tissus, quincaillerie et poissons en provenance des Flandres et d'Angleterre. Durant les premières décennies du $x v \|^{e}$ siècle, les registres d'entrée des navires signalent l'arrivée d'embarcations provenant des ports atlantiques des royaumes de Castille, du Portugal et de France dans des proportions assez proches (respectivement 87,72 et 70 bateaux), celles-ci étaient plus faibles depuis l'Angleterre et Terre Neuve (43 et 29 bateaux), ainsi que des Flandres, d'Allemagne, de Riga et de Moscovie.

Sur les côtes atlantiques castillanes, seuls les ports andalous maintinrent un trafic important. À la fin du $x v l^{e}$ siècle, les natifs exportèrent de Carthagène de l'alun, des teintures, de la salicorne ${ }^{38}$ et de la soie de Cadix. Juan Rodríguez embarqua en 1589 avec 154 quintaux de salicorne à son bord et, avec l'aide de Juan de Segovia, il assura l'envoi depuis Cadix de 468 quintaux de fer sur un navire de Málaga ${ }^{39}$. Les marchands de Cadix exportèrent à leur tour l'alun vers les Amériques ${ }^{40}$. Carthagène reçut en échange au $\mathrm{XVI}^{\mathrm{e}}$ siècle de la morue et du bois de Campeche ${ }^{41}$. En 1587, une saetía provençale transporta du bois de Campeche, du thon et des sardines de Cadix $^{42}$. Entre 1603 et 1617 presque la moitié des bateaux arrivèrent à Cadix avec des épices, du bois de Campêche et du Brésil, du tabac, du drap anglais, de la camelote, de la toile, du cuir, du cumin, du sucre, du raisin sec, de la salsepareille ${ }^{43}$, du gingembre, du blé, de l'orge, du thon, de la sardine et de la morue. Le tiers des bateaux provenant de Séville et de Sanlucar de Barrameda entre 1603 et 1617 étaient chargés de bois de Campeche et du Brésil, d'ébène, cuirs des Indes, laine, lin, cuir, sarzaparilla, gingembre, miel, blé, orge, olives et thon. Ayamonte et Huelva eurent un trafic bien plus faible : quelques bateaux transportant du thon, des sardines, du sucre, du vin et du blé. De Galice parvint un faible volume de toile, pommes, sardines et congres, tandis que deux bateaux apportaient régulièrement du sucre des Canaries. Enfin, dans les dernières décennies du $x v l^{e}$ siècle, on constate la commercialisation du fer de Biscaye. Cadix, Sanlúcar de Barrameda et Séville exportaient surtout des produits industriels, en général en provenance des Amériques. Des ports du sud de l'Andalousie venaient des pro-

38. Arch. prov. de Murcia, Prot. 5165, f० 190, 21-4-1589.

39. Arch. prov. de Murcia, Prot. $5169, f^{\circ} 80 v^{\circ}-84 v^{\circ}, 1592$.

40. En 1566, le Gênois Alberto Pinelo, exporta 2150 quintaux d'alun de Mazarrón : LORENZO SANZ, Eufemio, op. cit., 1979, p. 69.

41. Campeche : aujourd'hui un des États de la République fédérale du Mexique, situé dans la péninsule du Yucatan. Sous la dénomination " palo Campeche » ou " palo de Campeche » on désignait une essence de bois exotique utilisée pour obtenir une teinture rouge.

42. Arch. prov. de Murcia, Prot. 5164/2, $f^{\circ} 46 v^{\circ}-47 r^{\circ}, 23-12-1587$.

43. La salsepareille d'Europe est une plante de la famille des Smilacacées, répandue dans tout le bassin méditerranéen, dont la racine possède des vertus sudorifiques, dépuratives et nettoyantes du sang (Diccionario de la lengua española, Madrid, Real Academia española, 1970, art. « sarzaparilla »). 
duits alimentaires, notamment du poisson et des céréales, ainsi que des colorants.

Avec le Portugal, le commerce s'exerça de manière plus ou moins similaire entre Lisbonne et les ports du Sud. En effet, Faro et, dans une moindre mesure, Lagos et Setúbal offrirent une gamme de produits limitée : toile, sucre (vraisemblablement des Amériques), et de grandes quantités de poissons, tandis que Lisbonne redistribuait les épices et les colorants (cannelle, poivre, clous de girofle, camphre, bois de Brésil), des toiles des Indes, des étoffes, du sucre et du poisson. L'introduction de ces produits, attestée par les registres des bateaux dans les années 1604-1618, correspond à des marchés et à une demande portugaise et française mais provenant aussi des marchands de Carthagène. En effet, Juan Bautista Lamberto donna pouvoir en 1630 à René Peletier, marchand français habitant Lisbonne, pour acheter 1000 à 1500 barils de thon, afin que la marchandise soit découpée et envoyée à Carthagène avec les navires qu'il trouverait ${ }^{44}$. En sens inverse, Lisbonne reçut de Carthagène de la salicorne et du sparte ${ }^{45}$. En 1592, par exemple, Alonso Álvarez de Fuensalida, marchand de Carthagène et d'Oran affréta une saetia d'Arles pour emporter à Lisbonne 400 quintaux de salicorne et le reste de sparte. Miguel de la Peña, marchand de Grenade, fit assurer trois bateaux de 858 quintaux et 1601 arrobas $^{46}$ de salicorne et 54 milliers de sparte vers la même destination ${ }^{47}$. En 1601, Gaspar de Salafranca affréta avec plusieurs marchands de Carthagène, Tolède, et Lisbonne une saetia de 258 quintaux de salicorne et 40 sacs d'alun pour Lisbonne ${ }^{48}$. Trente ans plus tard, cette exportation à destination de Lisbonne se poursuivait, et Juan Francisco Tacón, marchand génois, affréta une flotte catalane pour envoyer 350 milliers de sparte ${ }^{49}$.

Sur la façade atlantique de la France, durant les deux dernières décennies $d u x l^{e}$ siècle, un important trafic se maintint avec la Bretagne, principalement avec Saint-Malo et Morlaix, grâce à la participation de marchands bretons installés à Carthagène qui exportaient de l'alun, du savon, de la laine et du sel de Carthagène et de Mazarrón (le sel provenait également d'Alicante et d'Ibiza). Ils importaient de la toile, du poisson et du blé. Un Malouin se plaignit en 1585 auprès de la municipalité de Carthagène du coût élevé des impôts royaux et provinciaux sur les ventes de poissons. En 1587, Guillaume Grave et Guillaume Harizon, habitants de Saint-Malo, affrétèrent une flotte provençale pour Almería et Carthagène ${ }^{50}$, tandis que Julien Jonchée vendait de la toile à Carthagène et envoyait de l'alun, du savon, de

44. Arch. prov. de Murcia, Prot. 5298, fo 137, 30-4-1630.

45. Plante de la famille des graminées dont les feuilles, après rouissage, servent à fabriquer des cordes ou de la pate à papier.

46. Unité de mesure des volumes qui varie selon les provinves et les produits.

47. Arch. prov. de Murcia, Prot. 5169, $f^{\circ} 121 r^{\circ}-122 r^{\circ}, 157 r^{\circ}-158 r^{\circ}, 284 r-285 r$ et $299 r^{\circ}-300 v^{\circ}: 21-3,6-5,11$ et $19-9-1592$.

48. Arch. prov. de Murcia, Prot. $5185, f^{\circ} 173 r^{\circ}-175 v^{\circ}$ et $177: 30-3$ et $1-4-1601$.

49. Arch. prov. de Murcia, Prot. $5298, f^{\circ} 217 v^{\circ}-218 v^{\circ}: 16-7-1630$.

50. Arch. prov. de Murcia, Prot. 5164/2, $f^{\circ} 11 v^{\circ}-12 r^{\circ}$ et $45 v^{\circ}-47 r^{\circ}: 7$ et 23-12-1587. 
la laine et du sel à Saint-Malo ${ }^{51}$. L'importance du trafic entre la Bretagne et I'Espagne au cours des deux dernières décennies du $x v I^{e}$ siècle est mise en évidence par l'activité de la compagnie de Diego Dorda et Guillaume Junge, habitants de Saint-Malo, avec Julián Junge, originaire de Saint-Malo, habitant et échevin de Carthagène, qui était respectivement leur beau-frère et leur frère. En 1590, ils expédièrent des marchandises vers Carthagène pour un montant de 2668080 de maravédis. Le 25 février 1591, Julien Coronel, lui aussi Breton et résidant à Carthagène, déclara avoir reçu le tiers de ce qui correspondait aux deux Malouins et fait état de six livres de comptes qui se trouvaient entre les mains du corregidor de Murcie $^{52}$.

Dans les années 1603-1617, les registres des entrées des embarcations attestent l'existence d'un trafic entre Carthagène et les ports bretons comme Saint-Malo, Brest, Nantes et d'autres ports plus méridionaux comme les Sables-d'Olonne et La Rochelle. Les produits provenant de Saint-Malo étaient la toile, le bois, le chanvre, le blé et la morue; des Sables-d'Olonne venaient du blé et du thon, tandis que les autres ports exportaient principalement du blé, de l'orge, du seigle, de la morue, des châtaignes, du riz et de la laine. Une des principales fonctions des ports bretons était la redistribution des produits hollandais (principalement de la toile) et anglais ${ }^{53}$, qui étaient transportés à Marseille. Par sa position, Saint-Malo jouait un rôle de premier plan dans ces échanges.

En 1630, Marc Fustier, habitant de Martigues et propriétaire d'une tartane, fut inculpé pour avoir introduit illégalement du tabac d'Oran. Juan de Rojas, qui affrétait des galères à Naples, demanda à Juan Fonseca de Chaves, de Madrid, de suivre pour lui les plaintes portées devant le tribunal de l'amirauté contre les propriétaires de trois navires de Saint-Malo accusés de contrebande pour avoir redistribué des produits des Amériques ${ }^{54}$. La rupture des relations de I'Espagne avec les Flandres et I'Angleterre à la fin du $x v^{e}$ siècle plaça la France en situation d'intermédiaire et donna naissance à un axe maritime avec la Bretagne, point de concentration des marchandises des Flandres et de la Hollande. Cela explique d'une certaine manière la domination française, encore plus importante si on considère les échanges de Carthagène avec les deux façades maritimes françaises au début du XVII siècle. Alicante et Carthagène constituèrent le centre d'intérêt privilégié de la France en raison d'une offre de produits qui répondait à une forte demande dans les Flandres et en Angleterre, notamment l'alun et le sel. L'affermage des salines de la Mata, Mazarrón et Carthagène par le commerçant breton Julián Junge permit à ce dernier d'expédier le sel

51. Arch. prov. de Murcia, Prot. 10778, fo 92-93, 25-8-1581; 5163, fo $26 r^{\circ}-27 r^{\circ}, 6-3-1590$; $5359, f^{\circ} 241 r^{\circ}-253 r^{\circ}, 13-9-1600$.

52. Arch. prov. de Murcia, Prot. $5163, f^{\circ} 73 v^{\circ}-74 v^{\circ}$.

53. Gómez-Centurión Jiménez, Carlos, Felipe II, La Empresa de Inglaterra y el comercio septentrional (1566-1609), Madrid, Editora Naval, 1988, p. 163, 205 et 216.

54. Arch. prov. de Murcia, Prot. 5298, $f^{\circ} 2 r^{\circ}-3 r^{\circ}$ et $106,3-1$ et 1-4-1630. 
directement vers l'Angleterre et les Flandres ${ }^{55}$. En 1630, le capitaine Josselin Haçou embarqua sur l'Espérance, navire de 70 tonneaux dont Pierre Argot était le propriétaire, ayant à son bord 18 marins et 6 pièces d'artillerie, pour rejoindre Alicante et Carthagène en 4 jours afin de charger 1000 quintaux de savon et les rapporter à Saint-Malo ${ }^{56}$. Enfin, il faut signaler les échanges avec des régions variées, caractérisées par leur éloignement, comme I'Irlande, les villes hanséatiques, la Russie et l'Amérique.

Carthagène entretint des échanges avec l'Angleterre durant les deux premiers tiers du $\mathrm{xvl}^{\mathrm{e}}$ siècle. L'alun de Murcie fut la principale exportation vers ce pays, mais l'interruption des relations en 1563-1564, 1568-1573, 1585$1604,1625-1630$ y 1655-1659 fit passer le transport des marchandises aux mains des Français ou par les voies détournées de la contrebande. Durant les deux premières décennies $d u x_{V} I^{e}$ siècle, on constate, à la faveur de la paix, une augmentation progressive du nombre de bateaux transportant de l'étain, du plomb, du blé, de l'orge, de la morue, du congre et des sardines à destination de l'Angleterre : 4 en 1603-1604 avant la paix, 12 en 1605-1606, 6 en $1612-1613$ et 19 en 1616-1617, ce qui peut expliquer la présence de consuls anglais dans la péninsule Ibérique. Durant la période antérieure, des bateaux anglais débarquèrent avec du drap de Londres. En 1630 ils apportaient des sardines, du congre, du plomb et des draps.

Le rétablissement officiel des relations avec les Flandres entre 1609 et 1621 est confirmé par les registres des embarcations de 1612-1613 et 1616-1617 (respectivement 4 et 8 bateaux alors qu'aucun n'a été recensé au cours des années 1603-1604 et 1605-1606). Les relations entre la Méditerranée et la Baltique s'intensifièrent à la fin $d u x v^{e}$ siècle non seulement grâce aux liens établis par l'Espagne mais également l'Italie. Les échanges de l'Espagne avec la Hanse augmentent à partir de 1583-1584 de par la volonté de Philippe II et d'Alexandre Farnèse de chasser les Hollandais et les Anglais du trafic ${ }^{57}$. Dans les années 1603-1617 on enregistra aussi l'arrivée de navires irlandais (Kinsale), de Hambourg et de la Baltique (Norden, Riga et Moscou).

Le trafic direct avec les Amériques fut au début du XvII ${ }^{\mathrm{e}}$ siècle plus important que celui qui a été décrit précédemment dans notre étude. Ainsi, arrivèrent de Terre-Neuve à destination de Carthagène entre les années

55. Sur l'importance de ce produit pour les Hollandais, voir ISRAEL, Jonathan I., " Los embargos españoles y la lucha por el dominio del comercio mundial », Revista de Historia Naval, t. 23, Madrid, 1988, p. 89-105, cfr. 93-95. Des bateaux anglais, français et hollandais arrivèrent déjà $\mathrm{au} x \mathrm{xv}^{\mathrm{e}}$ siècle jusqu'aux salines d'Alicante pour acheter du sel : CARANDE, Ramón, "La navegación y el comercio en el Mediterráneo durante el siglo XVI », en Otros siete estudios de historia de España, Barcelona, 1978, p. 260. LóPEZ MARTín, Ignacio, «Entre la guerra económica y la persuasión diplomática: el comercio mediterráneo como moneda de cambio en el conflicto hispano-neerlandés (1474-1609) ", Cahiers de la Mediterranée [En ligne], $\mathrm{n}^{\circ} 71,2005$, mis en ligne le 13 mai 2006, consulté le 27 juillet 2010. [http://cdlm. revues.org/index955.html].

56. Arch. prov. de Murcia, Prot. 5226, $\mathrm{f}^{\circ} 75 \mathrm{r}^{\circ}-76 \mathrm{r}^{\circ}, 10-5-1630$.

57. GómeZ-Centurión JiméneZ, Carlos, op. cit., 1988, p. 221-230. 
1603-1617, un total de 43 navires (soit une moyenne de 10 par an) chargés de morue, mais également de plomb, de toile et de sardines. Les Malouins participèrent à la pêche de la morue à Terre-Neuve et la transportèrent jusqu'à Carthagène. Le 24 décembre 1605, Jean Grute, capitaine de la Sainte-Catherine de Saint-Malo déclara avoir quitté Saint-Malo huit mois plus tôt pour aller pêcher la morue à Terre-Neuve et de là s'être dirigé vers Carthagène où il avait déchargé la plus grande partie de sa cargaison. II demandait l'autorisation d'embarquer 6 quintaux de biscuits pour approvisionner son équipage, ce qui lui fut accordé par l'alcalde mayor ${ }^{58}$.

Mais les relations avec le continent américain ne se limitèrent pas seulement à cet espace qui était en réalité une zone de pêche basque, française et anglaise, où l'on capturait de la morue et des baleines que l'on commercialisait ensuite ${ }^{59}$. À partir de 1529, Charles-Quint autorisa le commerce avec l'Amérique à partir des ports de Saint-Sébastien, Bilbao, Laredo Avilés, La Corogne, Cadix et Málaga, avec I'obligation d'un contrôle à Séville au retour. Selon Charles H. Haring cette licence fut retirée en 1573 aux ports du nord ${ }^{60}$. Par ailleurs, ce trafic fut rapidement organisé en flottes pour assurer une plus grande sécurité. Elles partaient de Séville et devaient en principe y revenir même si la fraude provoqua une grande dispersion tant à l'aller - Cadix et Sanlúcar de Barrameda bénéficiant d'une meilleure position géographique - qu'au retour, car les bateaux se dirigeaient directement vers le Portugal, le nord de l'Europe ou le bassin méditerranéen. Des marchands de Carthagène se lancèrent sur la route des Indes, en direction du Brésil ou d'autres endroits. Ils organisèrent surtout le transit des marchandises provenant d'Amérique via Séville et Cadix ${ }^{61}$. À titre d'exemple, Julián Junge possédait en 1600 trois bateaux dont l'un était partagé avec Diego Benvengud Rosique et Nicolas Pérez, échevins de Carthagène, dans le cadre d'une association avec Pedro de Lao, habitant à Cadix mais Flamand d'origine. Les deux autres bateaux transportèrent du vin et de l'huile depuis Séville jusqu'à Pernambuco et revinrent chargés de sucre et de bois de Brésil, qu'ils déchargèrent entre Lisbonne et Séville. L'autre bateau, le San Flugencio y Santa Florentina fut affrété à Carthagène par ses propriétaires à Pedro de Lao pour un voyage à Cadix et Pernambuco. Il revint en juillet, où il fut à nouveau loué par son capitaine au Génois Octavio Corvari pour rejoindre Oran et transporter des vêtements et du cuir à Livourne ${ }^{62}$. Dans son testament daté du 13 septembre 1600, Julián Junge déclara avoir fait alliance avec Pedro de Lao lorsqu'il avait investi 10000 ducats dans trois bateaux dont le dernier devait partir pour le Brésil, et dans lequel il était prêt à investir 1500 ducats supplémentaires si Pedro de Lao les lui deman-

58. Arch. mun. Cartagena, caja $90, \mathrm{n}^{\circ} 33$.

59. GuiaRd y LARRAURI, Teófilo, 1972 [1913], Historia del Consulado y Casa de Contratación de Bilbao y del comercio de la villa, t. I, Bilbao, p. 132-144. Prıotrı, Jean-Philippe, Bilbao et le commerce européen (vers 1520-vers 1620), Lille, Presses du Septentrion, 2002.

60. HaRING, Charles H., op. cit., 1918, p. 18-21. LoREnzo SANZ, Eufemio, 1979, t. 1, p. 305-306.

61. El oro fue otro ejemplo: LoRENZo SANZ, Eufemio, op. cit., 1979, p. 158.

62. Arch. prov. de Murcia, Prot. 5359, $f^{\circ} 33 r^{\circ}-34 v^{\circ}$ et $185 v^{\circ}-187 r^{\circ}, 7-2-1600$ et 19-7-1600. 
dait, car il ne voulait pas que le trafic et sa coopération s'interrompissent, sauf si sa vie le lui imposait ${ }^{63}$.

L'activité marchande se poursuivait encore en 1631 comme l'indique la procuration donnée par lacomo Rato, Génois, regidor de Carthage, à Juan Lorenzo Panés, résidant à Cadix, afin de percevoir tout ce qui avait été envoyé et engagé au retour de la flotte ${ }^{64}$. Peut-être cette intervention étaitelle due à la crise du milieu financier sévillan après le désastre de Matanzas (1638) qui vit la destruction de la flotte espagnole par les Hollandais ${ }^{65}$.

L'activité des marchands, les moyens et les zones d'échange maritime démontrent qu'Alicante et Carthagène, comme les autres ports du Levant, furent des terminaux portuaires et des villes marchandes autonomes qui permirent l'exportation de produits locaux et régionaux, même si ces fonctions furent partagées avec Valence et, dans une certaine mesure, avec Mazarrón, notamment durant la première moitié $\mathrm{du} \mathrm{xvl}^{\mathrm{e}}$ siècle. Par ailleurs, Alicante et Carthagène constituèrent principalement des ports d'escale ou de passage, ce qui entraîna pour ces villes des avantages et des inconvénients, avec d'une part un approvisionnement important de produits alimentaire et d'autre part une certaine forme de dépendance. Par ailleurs, ces deux ports s'appuyèrent sur des centres manufacturiers et navals européens dans un trafic parfois inégal. En ce sens, Alicante et Carthagène s'insérèrent pleinement dans les routes génoises, vénitiennes, livournaises et marseillaises (à partir de la fin $d u x v^{e}$ siècle), mais également dans les zones de redistribution de l'Andalousie atlantique, puisqu'elles envoyèrent des bateaux vers les Amériques, I'Angleterre et même la Baltique. En sens inverse Carthagène et Alicante accueillirent des navires à destination des ports français et italiens ou des bateaux chargés de produits américains. Ce trafic reflète particulièrement la transition entre la consommation de draps (caractéristique du XvI ${ }^{\mathrm{e}}$ siècle) et celle de la toile propre au XvII ${ }^{\mathrm{e}}$ siècle.

II convient d'ajouter à ces routes de longue distance, d'autres moins importantes avec des flux plus réduits mais qui jouèrent un rôle tout aussi important comme la route des îles qui unit Alicante et Carthagène avec Gênes, Livourne, la Sicile et Venise, la route d'Oran qui attira notamment des Catalans, des Valenciens et des Carthaginois, ou encore la route andalouse qui attira elle aussi ces mêmes marchands et vit circuler une grande quantité de produits coloniaux et alimentaires, redistribués ensuite en Castille depuis Alicante et Carthagène ou réexpédiés vers le Levant espagnol et l'Italie.

63. Arch. prov. de Murcia, Prot. 5359, fo $241 v^{\circ}-246 r^{\circ}, 13-9-1600$. La veuve donna pouvoir pour endre les comptes seulement le $1^{\text {er }}$ décembre 1600 (Arch. prov. de Murcia, Prot. $5359, f^{\circ} 370 r^{\circ}-371 r^{\circ}$ ).

64. Arch. prov. de Murcia, Prot. 5323, f $284,23-9-1631$.

65. EluıOT, John, El Conde Duque de Olivares, Barcelona, Crítica, 1990, p. 364-369. 
L'intervention des marchands d'Alicante et Carthagène dans le trafic avec I'Amérique, en particulier pour les bateaux, les marchandises et les transactions, démontre la croissance de ce groupe composé à la fois de marchands étrangers (principalement génois et français) et locaux qui réussirent à développer leur propre marine marchande et à prendre part à toutes les activités commerciales. II est aisé de déduire de cela ce que fut la participation de Valence et de Málaga, villes portuaires disposant d'un volume commercial et d'un nombre de marchands encore plus importants. Enfin, il est important de souligner la participation essentielle de Bretons dans ce trafic. Marchands et propriétaires de bateaux, ils intégrèrent les marchés et le commerce d'Alicante et de Carthagène dans les années 15781590 et leur participation fut active jusqu'en 1635. Elle reprit à partir de 1659, c'est-à-dire après la paix des Pyrénées, même si les Anglais obtinrent à cette époque une position privilégiée.

\section{Annexe 1- références bibliographique}

Agüera Ros, José Carlos, "Los modelos flamencos en la pintura murciana del siglo XVII », Verdolay, 6, 1994, Murcia, p. 143-152.

AIRALDI, G., Genova e Spagna nel secolo xv : II Liber damnificatorum in regno Granate (1452). Genova, 1966.

Alonso GarCíA, David, « Una nación, diferentes familias, múltiples redes. Genoveses en Castilla a principios de la Edad Moderna », dans : CRESPO SOLANA, Ana coord., Comunidades transnacionales. Colonias de mercaderes extranjeros en el Mundo Atlántico (1500-1830), Madrid, Ediciones Doce Calles, 2010, p. 65-82.

BenNASSAR, Bartolomé, « Un crecimiento interrumpido », dans : LÉON, Pierre (dir.), La Apertura del mundo : ss. XIV-XVI, Madrid, 1979, p. 567-588.

BLANES ANDRÉs, Roberto, "El comercio marítimo de Alicante hacia Valencia en el segundo cuarto del Seiscientos (1626-1650)», Revista de Historia Moderna, t. 26, Alicante, 2008, p. 275-302.

BRUMONT, Francis, "Politique, religion et affaires : Pierre Assézat (vers 1515-1581) 》, Annales de Bretagne et des Pays de l'Ouest, t. 12, n 4, 2005, p. 147-156.

Bustos Rodríguez, Manuel, "Comercio y comerciantes en la Andalucía del Antiguo Régimen : estado de la cuestión y perspectivas », Obradoiro de Historia Moderna, t. 17, Santiago de Compostela, 2008, p. 43-76.

Brillı, Catia, "Mercaderes genoveses en el Cádiz del siglo xVIII. Crisis y reajuste de una simbiosis secular », dans : Crespo Solana, A. coord., Comunidades transnacionales. Colonias de mercaderes extranjeros en el Mundo Atlántico (1500-1830), Madrid, Ediciones Doce Calles, 2010, p. 83-102.

CANDEL CRESPo, Francisco, Familias genovesas en Murcia, Murcia, 1979.

CARANDE, Ramón, Carlos v y sus banqueros, Barcelona, Crítica, 2a ed., 1983.

CARRERE, Claude, Barcelona, centro económico en la época de dificultades, 1380-1462, París, 1967.

Chaunu, Pierre, Séville et l'Atlantique, 1504-1650, Paris, SEVPEN, 1955-1960.

ConCHA, Ignacio de la, "El Almirantazgo de Sevilla : Notas para el estudio de las instituciones mercantiles en la Edad Moderna », Anuario de Historia del Derecho Español, t. 19, Madrid, 1948, p. 459-525.

Crespo Solana, Ana, "Comunidad y familia versus nación en el marco atlántico. Cooperación y competencia en las redes de negociantes flamencos (1690-1760) », 
dans : CRESPo Solana, Ana dir., Comunidades transnacionales. Colonias de mercaderes extranjeros en el Mundo Atlántico (1500-1830), Madrid, Ediciones Doce Calles, 2010, p. 47-61.

Descimon, Robert/Ruiz IbáñEz, José Javier, Les Ligueurs de l'exil. Le refuge catholique français après 1594, Seyssel, Champ Vallon, 2005.

Domínguez Ortiz, Antonio, "El Almirantazgo de los Países septentrionales y la política de Felipe II », Hispania, Revista Española de Historia, t. 27, Madrid, 1947, p. 272-290.

ELıIOTT, John, El Conde Duque de Olivares, Barcelona, Crítica, 1990.

Figueras Pacheco, Francisco, El Consulado Marítimo y Terrestre de Alicante y Pueblos del Obispado de Orihuela, Alicante, Instituto de Estudios Alicantinos, 1957.

Franch Benavent, Ricardo, "El comercio en el Mediterráneo español durante la Edad Moderna : del estudio del tráfico a su vinculación con la realidad productiva y el contexto social », Obradoiro de Historia Moderna, t. 17, Santiago, 2008, p. 77-112.

García Fuentes, Lutgardo, El comercio español con América : 1650-1700, Sevilla, Diputación Provincial de Sevilla-Escuela de Estudios Hispanoamericanos, 1980, p. 87-89.

Gómez-Centurión JimÉnez, Carlos, Felipe II, la empresa de Inglaterra y el comercio septentrional (1566-1609), Madrid, Editora Naval, 1988.

González Gallego, I. «El Libro de los privilegios de la nación genovesa », Historia, Instituciones, Documentos, t. 1, 1974, p. 275-358.

GRENDI, Edoardo, "Trafico portuale, navigilio mercantile e consolati genovesi nel Cinquecento", Revista Storica Italiana, t. 80, 1968, p. 591-629.

GRENDI, Edoardo, La Repubblica aristocratica dei genovesi : Política, carità e commercio fra Cinque e Seicento, Bolonia, II Mulino, 1987.

Guiard y LarRauri, Tomás, Historia del Consulado y Casa de Contratación de Bilbao y del comercio de la villa, t. I, Bilbao, 1972 [1913].

HeERs, Jaques, "Le royaume de Grenade et la politique marchande de Gênes en Occident », Moyen Âge, t. 1-2, 1957, p. 81-127.

ISRAEL, Jonathan I., "Spanish Wool Exports and the European Economy, 1610-1640 », The Economic History Review, t. 33, n. 2, 2a serie, 1980, p. 193-211.

Lapeyre, Henri y CaRANDE, Ramón, "Relaciones comerciales en el Mediterráneo durante el siglo XVI », dans : VI Congreso de Historia de la Corona de Aragón, Madrid, 1959, p. 697-800.

LAPEYRE, Henri, «El libro de cuentas de Baltasar Julia, hombre de negocios valenciano (1565) », Cuadernos de Historia de España, n. 51, 1970, p. 246-315.

LAPEYRE, Henri, El Comercio exterior de Castilla a través de las aduanas de Felipe II, Valladolid, Universidad de Valladolid, 1981.

LÓPEZ, Robert S., « II predominio económico dei genovesi nella monarchia spagnola », Giornale Storico e Literario Della Liguria, XII/2, 1936, p. 3-18.

López de Coca Castañer, José Enrique/Torres Beltrán, Ma Teresa, "Mercaderes genoveses en Málaga (1487-1516) : Los hermanos Centurión e Ytalián », Historia, Instituciones, Documentos, t. 7, Sevilla, 1980, p. 93-126.

López Beltrán, Ma Teresa, "Documentos sobre Málaga y el tráfico con las Indias ", Baetica. Estudios de Arte, Geografía e Historia, t. 12, Málaga, 1979, p. 169-173.

LYNCH, John, España bajo los Austrias, Barcelona, Península, 1971.

Maestre de San Juan Pelegrín, Federico, "La actividad comercial de Alicante y Cartagena. Similitudes, diferencias y comunidades mercantiles (1643-1660) », Espacio, Tiempo y Forma (Ha Moderna), serie Iv, t. 20, Madrid, 2007, p. 95-119.

Malamoud, C.D. Cádiz y Saint Maló en el comercio colonial peruano (1698-1725), Jerez de la Frontera, 1986. 
Maldonado, Leonor, « Negocios e integración social del comerciante marsellés Pedro Choly ", Revista de Historia Moderna, t. 11, Alicante, 1992, p. 79-93.

MARTínez GIJÓN, José, «La práctica del comercio por intermediario en el tráfico con las Indias durante el siglo XVI », Anuario de Historia del Derecho Español, t. 40, Madrid, 1970, p. 5-83.

MAS Galvañ, Cayetano, "Artesanía, manufacturas y actividades comerciales », dans : Historia de la Provincia de Alicante, Murcia, Ediciones Mediterráneo, 1986, p. 125212.

MELIS, Federico, "Málaga nel sistema economico del XIV e Xv secolo », Mercaderes italianos en España (siglos XIV-XvI), Sevilla, Universidad de Sevilla, 1976, p. 3-65.

Molas Ribalta, Pere, "Instituciones y comercio en la España de Olivares », Studia Histórica, t. 5, Salamanca, 1987, p. 91-98.

Molina Molina, Ángel Luís, "Mercaderes genoveses en Murcia durante la época de los Reyes Católicos », Miscelánea Medieval Murciana, vol. 2, Murcia, 1976, p. 277-312.

Montojo Montojo, Vicente, Cartagena en la época de Carlos v. Crecimiento demográfico, transformaciones económicas y conflictividad social, Murcia, Academia Alfonso X el Sabio, 1987.

Montojo Montojo, Vicente/Maestre de San Juan Pelegrín, Federico, "Relaciones sociales y actividades económicas de los comerciantes procedentes de los Pirineos franceses en Cartagena (España) a lo largo del siglo XVIII ", MINOVEZ, Jean-Michel et Poujade, Patrice (dir.)., Circulación de las mercancías y redes comerciales en los Pirineos, siglos XIII-XIX (Coloquio, Andorra la Vella, 1-4.10.2003), Toulouse, 2005, p. 191-211.

Montojo Montojo, Vicente, "El comercio de Alicante en los reinados de Felipe ॥ y Felipe III. Una construcción desde la cooperación », Cuadernos de Historia Moderna, t. 32, 2007, p. 87-111.

Montojo Montojo, Vicente, "Los comerciantes de Alicante y Cartagena en la Guerra de Sucesión », Estudis. Revista de Historia Moderna, t. 34, Valencia, 2008, p. 219239.

Montojo Montojo, Vicente, "El comercio de Alicante a mitad del siglo xVII según los derechos y sisas locales de 1658-1662 y su predominio sobre el de Cartagena », Murgetana, t. 122, 2010, p. 37-60.

Pérez de Colosía Rodríguez, Ma Isabel, « Embargo de navíos holandeses en el puerto de Málaga (1623-1624) », Baética : Estudios de Arte, Geografía e Historia, t. 3, Málaga, 1980, p. 207-247.

Perpillou, Maurice, Géographie de la circulation : La navigation et les transports maritimes, París, 1960.

PhilliPS, Carla R., «The Spanish Wool Trade, 1500-1780 », Journal of Economic History, t. 47,1982, p. $775-795$.

PIKE, Rut, Aristócratas y comerciantes. La sociedad sevillana en el siglo XVI, Barcelona, Ariel, 1978.

PRIOTTI, Jean-Philippe, "Guerre et expansion commerciales : le rôle des Basques dans l'empire espagnol au xvle siècle », Revue d'Histoire Moderne et Contemporaine, t. $48-2 / 3,2001$, p. 51-71.

PRIOTTI, Jean-Philippe, "Réseaux sociaux basques, commerce transocéanique et pouvoir local au XVII e siècle ", Annales de Bretagne et des Pays de l'Ouest, t. 12, $n^{\circ} 4,2005$, p. 183-200.

Pulz, Antoine M., « Marchands genevois du monde méditerranéen (vers. 1600-1630) », Histoire économique du monde méditerranéen 1450-1600 (Mélanges en l'honneur de Fernand Braudel), Toulouse, Privat, 1973, p. 460-463. 
Ringrose, David R., "Perspectivas on the Economy of Eigteenth Century Spain », dans : Historia Ibérica, vol. 3, Madrid, Anaya, 1973, p. 59-101.

Ringrose, David R., Madrid y la economía española, 1560-1850, Madrid, Alianza Editorial, (traducción de versión original inglesa de 1983), 1985, p. 237-238.

RuIz IBÁNEZZ, José Javier, «Entre Dios y los hombres : Los refugios políticos en la Alta Edad Moderna Europea », dans : M. GonzÁlez JimÉnEZ et al. Acogidos y rechazados en la historia, Valladolid, 2005, p. 35-84.

SAlvador Esteban, Emilia, "Mercaderes extranjeros en la Valencia de los siglos XVI y XVII. Entre la atracción y el rechazo », dans : Congreso Internacional La Burguesía española en el Antiguo Régimen (Madrid, 1991), Valladolid, Universidad, 1996, p. 1138-1155.

SAmsonowicz, Henri, "Relations commerciales entre la Baltique et la Méditerranée aux $x \mathrm{Vl}^{\mathrm{e}}$ et XVIIe siècles ", dans : Histoire économique du monde méditerranéen : 1450-1650 (Mélanges en l'honneur de Fernand Braudel), Toulouse, Privat, 1973, p. 537-545.

SAUPIN, Guy, "Les marchands espagnols dans l'élite dirigeante du Conseil des bourgeois de Nantes au milieu du Xv| ${ }^{e}$ siècle ", Annales de Bretagne et des Pays de I'Ouest, t. 12, n 4, 2005, p. 157-181.

SelLa, Domenico, "Crisis and change in Venetian trade », dans : Crisis and Change in the Venetian Economy in the $16^{\text {th }}$ and $17^{\text {th }}$ Centuries, London, 1968.

TouCHARD, Henri, « Marins bretons et marins espagnols dans les ports anglais à la fin du Moyen Age », Cuadernos de Historia (Anexos de Hispania), t. 2, Madrid, 1968, p. 81-91.

TorRes Fontes, Juan, "Genoveses en Murcia (siglo xv) », Miscelánea Medieval Murciana, vol. 2, Murcia, 1976, p. 69-168.

Torres SÁnchez, Rafael, "La colonia genovesa en Cartagena durante la Edad Moderna », en Rapporti Genova-Mediterraneo-Atlantico nell'età moderna, Génova, Universidad de Génova, 1990, p. 553-581.

VAN Houte, Jean A./Stols, Edy, "Les Pays Bas et la Méditerranée atlantique au $\mathrm{xV}^{\mathrm{e}}$ siècle ", in Histoire économique du monde méditerranéen : 1450-1600 (Mélanges en I'honneur de Fernand Braudel), Toulouse, Privat, 1973, p. 445-657.

VÁzQUeZ DE PRADA, Valentín, «La actividad económica del Levante español en relación con Italia a finales del siglo XVI », IV Congreso de Historia de la Corona de Aragón, Barcelona, 1957, p. 697-800.

VÁzQUeZ de PRADA, Valentín, « La colonia mercantil valenciana en Amberes en la época de Carlos V », en Homenaje a Jaime Vicens Vives, t. 2, Barcelona, Universidad de Barcelona, 1967, p. 733-754, reeditado en 1999, p. 207-227.

WeBer, Klaus, "Were merchants more tolerants? Godless Patrons of the Jews an the Decline of the Sephardi Community in Late Seventeeth-Century Hamburg", Jewish Culture and History, $\mathrm{n}^{\circ}$ 7/1-2, 2004, p. 77-92.

WEBER, Klaus, " La migration huguenote dans le contexte de l'économie atlantique (L'exemple de Hambourg, 1680-1800) », dans : Guido BrAUN et Susanne LACHENICHT, Les États allemands et les huguenots, Munich, Oldenbourg, 2007, p. 125-136. 


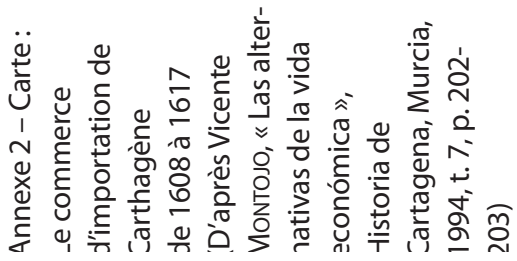

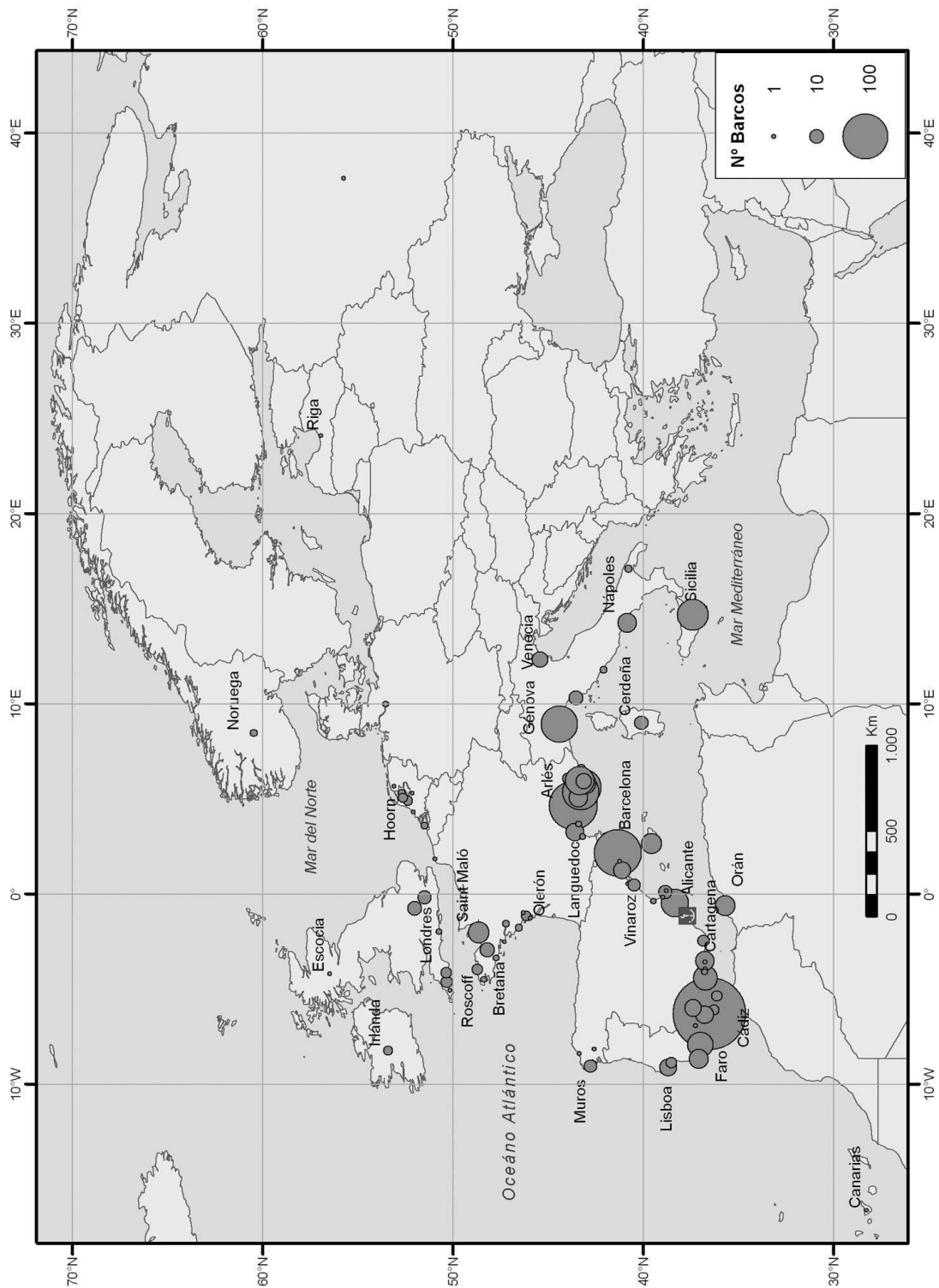


Les relations commerciales entre le Levant espagnol, I'Europe occidentale et l'Amérique

Annexe 3 - Les marchands valenciens,

catalans et aragonais à Anvers en 1540

(Source : Valentín Vázquez de Prada, La colonia mercantil valenciana,

2000 [1967], p. 212-217)

\begin{tabular}{|c|c|c|c|c|c|c|c|}
\hline $\begin{array}{l}\text { Ordonna- } \\
\text { teur }\end{array}$ & Résidence & Profession & Date & Action & Destinataire & Résidence & Profession \\
\hline $\begin{array}{l}\text { Simón, } \\
\text { Domingo }\end{array}$ & Anvers & $\begin{array}{l}\text { marchand } \\
\text { aragonais }\end{array}$ & $26 / 06 / 1540$ & $\begin{array}{l}\text { Fait } \\
\text { appel à }\end{array}$ & $\begin{array}{l}\text { Aguirre, } \\
\text { Pedro de }\end{array}$ & Londres & marchand \\
\hline $\begin{array}{l}\text { Simón, } \\
\text { Domingo }\end{array}$ & Anvers & $\begin{array}{l}\text { marchand } \\
\text { aragonais }\end{array}$ & $08 / 03 / 1540$ & $\begin{array}{l}\text { donne } \\
\text { pouvoir à }\end{array}$ & $\begin{array}{l}\text { Arana, } \\
\text { Cristóbal }\end{array}$ & \begin{tabular}{|l|} 
Pays \\
Basque
\end{tabular} & \begin{tabular}{|l|} 
maître de \\
navire
\end{tabular} \\
\hline Pérez, Luis & & $\begin{array}{l}\text { marchand } \\
\text { aragonais }\end{array}$ & $26 / 08 / 1540$ & \begin{tabular}{|l} 
Met en \\
demeure
\end{tabular} & \begin{tabular}{|l|} 
Simón, \\
Domingo
\end{tabular} & Anvers & \\
\hline $\begin{array}{l}\text { Simón, } \\
\text { Domingo }\end{array}$ & Anvers & $\begin{array}{l}\text { marchand } \\
\text { aragonais }\end{array}$ & $21 / 08 / 1540$ & $\begin{array}{l}\text { Met en } \\
\text { demeure }\end{array}$ & $\begin{array}{l}\text { Simon, } \\
\text { Jehan }\end{array}$ & Palerme & \\
\hline $\begin{array}{l}\text { Plano, } \\
\text { Arnau del }\end{array}$ & Anvers & & $27 / 07 / 1540$ & $\begin{array}{l}\text { Met en } \\
\text { demeure }\end{array}$ & Sentis, Juan & Anvers & marchand \\
\hline $\begin{array}{l}\text { Sadornil, } \\
\text { Frances }\end{array}$ & Anvers & $\begin{array}{l}\text { marchand } \\
\text { aragonais }\end{array}$ & $27 / 08 / 1540$ & \begin{tabular}{|l} 
Porte \\
plainte \\
contre
\end{tabular} & $\begin{array}{l}\text { Vargas, } \\
\text { Cristóbal }\end{array}$ & Medina & \\
\hline $\begin{array}{l}\text { Salazar, } \\
\text { Antonio }\end{array}$ & Anvers & $\begin{array}{l}\text { marchand } \\
\text { aragonais }\end{array}$ & $1 / 09 / 1540$ & $\begin{array}{l}\text { Porte } \\
\text { plainte } \\
\text { contre }\end{array}$ & $\begin{array}{l}\text { Simón, } \\
\text { Domingo }\end{array}$ & Anvers & marchand \\
\hline $\begin{array}{l}\text { Aliaga, } \\
\text { Francisco }\end{array}$ & Anvers & $\begin{array}{l}\text { marchand } \\
\text { valencien }\end{array}$ & $10 / 07 / 1540$ & $\begin{array}{l}\text { donne } \\
\text { pouvoir à }\end{array}$ & $\begin{array}{l}\text { Bartoloméi } \\
\text { Miquel }\end{array}$ & Majorque & bourgeois \\
\hline $\begin{array}{l}\text { Sadornil, } \\
\text { Frances }\end{array}$ & Anvers & $\begin{array}{l}\text { marchand } \\
\text { aragonais }\end{array}$ & $26 / 06 / 1540$ & $\begin{array}{l}\text { donne } \\
\text { pouvoir à }\end{array}$ & $\begin{array}{l}\text { Mazuelo, } \\
\text { Pedro }\end{array}$ & Londres & marchand \\
\hline $\begin{array}{l}\text { Simón } \\
\text { mayor, D. }\end{array}$ & Anvers & & $6 / 04 / 1540$ & Offre à & $\begin{array}{l}\text { Torres, } \\
\text { Cristóbal }\end{array}$ & & \\
\hline $\begin{array}{l}\text { Ferrer, } \\
\text { Belingar }\end{array}$ & Anvers & $\begin{array}{l}\text { marchand } \\
\text { aragonais }\end{array}$ & $19 / 01 / 1540$ & \begin{tabular}{|l|} 
donne \\
pouvoir à
\end{tabular} & $\begin{array}{l}\text { Carni, Jeró- } \\
\text { nimo }\end{array}$ & Valence & marchand \\
\hline $\begin{array}{l}\text { Ferrer, } \\
\text { Dimas }\end{array}$ & Anvers & $\begin{array}{l}\text { marchand } \\
\text { valencien }\end{array}$ & $5 / 06 / 1540$ & affrète & $\begin{array}{l}\text { Pedrós, } \\
\text { Jaime }\end{array}$ & Denia & $\begin{array}{l}\text { maître de } \\
\text { navire }\end{array}$ \\
\hline $\begin{array}{l}\text { Ferrer, } \\
\text { Dimas }\end{array}$ & Anvers & $\begin{array}{l}\text { marchand } \\
\text { catalan }\end{array}$ & $3 / 11 / 1540$ & $\begin{array}{l}\text { Met en } \\
\text { demeure }\end{array}$ & $\begin{array}{l}\text { Damnez, } \\
\text { Antonio }\end{array}$ & Medina & \\
\hline $\begin{array}{l}\text { Ferrer, } \\
\text { Dimas }\end{array}$ & Anvers & $\begin{array}{l}\text { marchand } \\
\text { aragonais }\end{array}$ & $11 / 12 / 1540$ & $\begin{array}{l}\text { donne } \\
\text { pouvoir à }\end{array}$ & \begin{tabular}{|l} 
Ferrer, \\
Berlingar
\end{tabular} & Anvers & marchand \\
\hline $\begin{array}{l}\text { Villa- } \\
\text { franca, } \\
\text { Honoré }\end{array}$ & Anvers & $\begin{array}{l}\text { marchand } \\
\text { aragonais }\end{array}$ & $11 / 12 / 1540$ & $\begin{array}{l}\text { Témoigne } \\
\text { pour }\end{array}$ & $\begin{array}{l}\text { Ferrer, } \\
\text { Berlingar }\end{array}$ & Anvers & marchand \\
\hline
\end{tabular}


Annexe 4 - Affrètements de bateaux à Cadix à destination de ou faisant escale à Carthagène (1550-1570)

(Source : M. Dolores Rojas Vaca, Una escribanía pública gaditana del siglo Xvı)

\begin{tabular}{|l|l|l|l|l|}
\hline \multicolumn{1}{|c|}{ Affréteur } & \multicolumn{1}{|c|}{ Résidence } & \multicolumn{1}{c|}{ Produit } & \multicolumn{1}{c|}{ Destination et escales } & Date et nombre \\
\hline Pedro Leal & Barcelone & thon & Faro-Alicante-Barcelone & 18-7-1550,4 \\
\hline Jaime Calvet & Cadix Catalan & prêts & Cadix-Civitavecchia & $16-9-1550,8$ \\
\hline Fco. Barbarán & Cadix Catalan & prêts & Cadix-Alicante (Jmo. Bernar) & 6-10-1550, 10 \\
\hline Benito Gil & Cadix Majorquin & prêts & Cadix-Alicante-Mallorca & $3-11-1550,13$ \\
\hline Pedro Vilar & Cadix Catalan & manuf. & Cadix-Alicante-Barcelona & $21-11-1550,17$ \\
\hline Lázaro Pinelo & Cadix Génois & sucre & Cadix-Barcelone-Gênes & $22-1-1560,23$ \\
\hline Jmo. Capriata & Cadix Génois & sucre & Cadix-Barcelone-Gênes & $29-1-1560,24$ \\
\hline Jmo. Grillo & Cadix Génois & cochenille & Cadix-Barcelone-Gênes & $30-1-1560,26$ \\
\hline Pedro Castillo & Cadix & sucre & Cadix-Barcelone-Livourne & $30-1-1560,27$ \\
\hline Fco. de Santi & Cadix Florentin & sucre & Cadix-Alicante-Livourne & $3-4-1560,37$ \\
\hline Pedro Vilar & Cadix Catalan & thon & Conil/Barbate-Barcelone & $18-5-1560,44$ \\
\hline Juan Vendrel & Cadix Catalan & thon & Conil-Barcelone & $24-5-1560,45$ \\
\hline Juan Vendrel & Cadix Catalan & thon & Barbate-Barcelone & $25-5-1560,46$ \\
\hline Pedro Pascual & Alicante & thon & Conil-Alicante & $12-6-1560,49$ \\
\hline Pedro Vilar & Cadix Catalan & prêts & Cadix-Barcelone & $12-6-1560,50$ \\
\hline Agustín Pelerio & Génois & thon & Conil-Alicante & $25-6-1560,51$ \\
\hline Domingo Simón & Cadix & fer & Cadix-Alicante-Denia-Vala & $31-1-1570,82$ \\
\hline Pedro Castillo & Cadix & vin & $\begin{array}{l}\text { Cadix /Port Sainte-Marie } \\
\text { Barcelone }\end{array}$ & $25-2-1570,83$ \\
\hline Ag. Espínola & Cadix Génois & prêts & Cadix-Barcelone-Gênes & $6-7-1570,88$ \\
\hline Jmo. Calvo & Cadix Génois & prêts & Cadix-Barcelone & $6-7-1570,89$ \\
\hline Tomás Cibo & Cadix Génois & prêts & Cadix-Barcelone & $15-7-1570,91$ \\
\hline
\end{tabular}


RÉSUMÉ

L'intervention des marchands d'Alicante et de Carthagène dans les activités liées aux bateaux, aux marchandises et aux transactions dans le trafic avec l'Amérique démontre l'accroissement de ce groupe composé à la fois de marchands d'origine étrangère (principalement Génois et Français) et de marchands locaux qui parvinrent à développer leur propre marine marchande et à prendre part à toutes les activités commerciales. II est aisé de déduire ce que fut également la participation de villes comme Valence et Málaga, villes portuaires comptant un volume commercial et un nombre de marchands encore plus importants. La participation de commerçants bretons dans ce trafic fut essentielle. Les Bretons, commerçants et propriétaires de bateaux de longue date, intégrèrent les marchés et le commerce d'Alicante et de Carthagène dans les années 1578-1590. Leur participation fut active jusqu'en 1635 et reprit à partir de 1659, c'est à dire après la Paix des Pyrénées, même si les Anglais obtinrent à cette époque une position et une situation privilégiées.

\section{ABSTRACT}

The intervention of the merchants of Alicante and Cartagena in the traffic with America, as regards ships, goods and deals, shows the growth of this group, composed both of foreign traders (chiefly Genoese and French) and local merchants who succeeded in developing their own mercantile navy and taking part in all the commercial activities. It is easy to deduce what the participation of towns like Valencia and Malaga was, both being seaports with an even more important mercantile activity and more merchants. The part played by Breton traders was an essential one. The Bretons, who had long been merchants and ship-owners, came into the markets and deals of Alicante and Cartagena in the years 1578-1590. They played an active part until 1635 and resumed their activity as from 1659, i.e. after the Peace of the Pyrenees, even though the English achieved a privileged position in those days. 
